The Covid-19 panic and the global North-South divide - A perspective

DOI:10.20529/IJME.2020.048.

Keywords: vector borne diseases, Covid-19, communicable diseases, public health emergency

J Krishnamurti, a renowned philosopher, describes fear as the transition from the convictions of the Known to the flux of the Unknown'. The weakening of the interspecies transmission barrier between the animal and human interface has strengthened this fear. Consequently, our impulsive selves have taken precedence over our reflective voices.

Some numbers from 2019 should put things in perspective: The National Centre for Disease Control reports 28,798 seasonal influenza $(\mathrm{H} 1 \mathrm{~N} 1)$ cases in our country with 1218 deaths (1), The National Vector Borne Disease Control Programme reports $1,36,422$ cases of dengue with 132 deaths, $3,34,693$ cases of malaria and 1,55,809 $\mathrm{p}$ falciparum cases with 50 deaths, 3128 cases of kala-azar, 14,464 acute encephalitis cases with 732 deaths, 2294 cases of Japanese encephalitis with 231 deaths, and 9477 chikungunya cases $(1,2)$. To top the burden, there is community acquired pneumonia, typhoid, UTIs, sepsis, whose national data is not available. Most of these numbers should be staggering enough to ring alarm bells; yet, there has been no panic. Diarrhoea is the third most common cause of death in under-five children, responsible for $13 \%$ deaths in this age-group, killing an estimated 300,000 children in India each year (3). There has not been a shortage of masks; sanitisers have not flown off the shelves and nothing remotely approaching a lockdown has occurred. Lack of safe drinking water has never been seen an emergency. All of these non-Covid-19 burdens seem to have lost their relevance now. Hospitals are restructuring themselves solely as Covid-19 "warzones".

It may be salutary to recall the herculean efforts that India has put in to eradicate a communicable disease - tuberculosis. TB is a far more deadly disease, than Covid-19 and has a wider range of transmissibility (4). RNTCP reports India had 21,50,000 notified TB cases in 2018 (5). Till this day, active TB does not have a serological rapid card detection test with high sensitivity and specificity for diagnosis. BCG has proven efficacy only in severe forms of TB in childhood and new cases of pulmonary TB continue to occur despite the high coverage of BCG. Since TB is just a disease of historical interest in more affluent countries with low burden, not many trials are underway in search of a better vaccine. The estimated cost of developing a safe and effective TB vaccine is reported to be around over 1.25 billion dollars (6), unaffordable for countries bearing the TB burden. Further complicating matters, is the bunch of vector-borne diseases (malaria, dengue, chikungunya, etc), which every year debilitate thousands of people in the country, waiting in line for candidate vaccines from over 50 years (7). While there is no silver lining in sight for these diseases, Covid-19 seems to have jumped the queue with billion dollar funding for the fastest ever development of vaccine in history.

A century ago, the global North was also fighting against polio, diphtheria and pertussis. The vaccines were introduced to the world then, shipped to the South after decades, and immunisation programmes began. Anti-tubercular therapy (including the latest Bedaquiline for MDR-TB) was developed for affluent societies, so was anti-retro viral treatment for HIV/ AIDS- both of which arrived much later in the South. The drug development pipeline indicates that of the 1,393 total new drugs approved between 1975 and 1999, only $1 \%$ (13 drugs) was specifically designated for a tropical disease (8). The situation has not changed much since then, with those for genetic disorders or cell and gene therapy (majority of them for cancer) taking away the major share of interest and funding resources in recent years (9). An anti-corona viral drug today is being pushed for early development with massive funding, biopharmaceutical companies up in the global north are working round the clock.

There has been a proliferation of global foundations, funds, action plans and big players (GAVI, PATH, WHO, UNICEF, Gates Foundation, MSF et al) striving to meet public health targets of disease control, elimination and eradication, articulated as MDGs and SDGs. As long as our healthcare system is not patient centric and fragmented into innumerable bureaucratic silos (communicable/noncommunicable diseases, tobacco, blindness, deafness, iodine, iron, thyroid, leprosy etc), it will continue to be hamstrung, and not just during epidemics. Further, our healthcare system is plagued by internal issues (or barriers) - no access to medicines, vested political interests, and out of pocket expenditure, a long list of ills (10). It shouldn't therefore require a Covid-19 to stir the already shaken health system. In the fight against the diseases of poverty, Philip Stevens writes eloquently that wealth creation is the only solution (11). While we express gratitude for what has been handed down by the global North, it is time to find our own feet. As Covid-19 takes the spotlight, a plethora of infectious diseases appear to be here to stay. If Covid-19 is a public health emergency, shouldn't the other communicable diseases with high burden also be?

SushmaKrishna (drsushmakrishna@gmail.com), Consultant Microbiologist and Public Health Specialist, St. Martha's Hospital, Nrupathunga Rd, Bengaluru, 560001 INDIA

Acknowledgement: The author would like to acknowledge the help of Shriram KS, Senior Scientist, GE Health Care, Bengaluru, for proof-reading. 
Note

http://jiddu-krishnamurti.net/en/commentaries-on-living-series1/1956-00-00-jiddu-krishnamurti-commentaries-on-living-series-1-58fear

References

1. National Centre for Disease Control. Seasonal influenza (H1N1) casesState/UT wise, Year-wise number of cases, deaths from 2013 to 2020 (till 23rd February, 2020). New Delhi: NCDC, MoHFW; 2020[cited 2020 Mar 31]. Available from: https://ncdc.gov.in/showfile.php?lid $=280$

2. National Vector Borne Disease Control Programme. Diseases. New Delhi: NVBDCP, MOHFW; 2020 [cited 2020 Mar 31]. Available from: https:// nvbdcp.gov.in/index4.php?lang=1\&level=0\&linkid $=407 \&$ lid $=3683$

3. Million Death Study Collaborators; Bassani DG, Kumar R, Awasthi S, Morris SK, Paul VK, et al. Causes of neonatal and child mortality in India: A nationally representative mortality survey. Lancet. 2010 Nov 27; 376 (9755):1853-60.doi:10.1016/S0140-6736(10)61461-4.

4. Callaway E, Cyranoski D, Mallapaty S, Stoye E, Tollefson J. The corona pandemic in five powerful charts. Nature News. 2020 Mar 18[cited 2020 Mar 31]. Available from: https://www.nature.com/articles/d41586-02000758-2

5. Central TB Division. India TB Report 2019. Revised National Tuberculosis Control Program.New Delhi:MoHFW;2019 [cited 2020 Mar 31]. Available from: https://tbcindia.gov.in/index1.php?lang=1\&level=1\&sublinkid=4 160\&lid $=2807$

6. Stop TB initiative. Global report on tuberculosis vaccines. 2018 [cited 2020 Mar31]. Available from: https://www.who.int/tb/publications/ global_report/gtbr2018_main_text_28Feb2019.pdf

7. LaBeaud AD, Aksoy S. Neglected funding for vector-borne diseases: $A$ near miss this time, a possible disaster the next time. PLoS Negl Trop Dis. 2010 Oct 26; 4(10): e847.

8. Trouiller P, Olliaro P, Torreele E, Orbinski J, Laing R, Ford N. Drug development for neglected diseases: a deficient market and a publichealth policy failure. Lancet. 2002 Jun 22; 359(9324):2188-94.

9. Pharmaprojects. Pharma R\&D Annual Review 2019. Pg 14-18. Available from: https://pharmaintelligence.informa.com/ /media/informa-shopwindow/pharma/2019/files/whitepapers/pharma-rd-review-2019whitepaper.pdf

10. Bajpai V. The challenges confronting public hospitals in India, Their origins, and possible solutions.Advances in Public Health.2014 Jul 13[cited 2020 Mar 31]. Available from: https://doi.org/10.1155/2014/898502

11. Stevens P. Diseases of poverty and the 10/90 gap. 2004 Nov [cited 2020 Mar 31]. https://www.who.int/intellectualproperty/submissions/ InternationalPolicyNetwork.pdf

\section{Ethics in the Covid-19 emergency: Examining rationing decisions}

DOI:10.20529/IJME.2020.049.

Keywords: Health care rationing, patient selection, health system resources, ethics, decision making.

"Place age limit for access to intensive care, [that is]

based on greatest possibilities of survival."

Early last month, the Italian Society of Anaesthesia was forced to publish the above guideline (1) for the country's hospitals. Besides the rising cases of infection, the doctors realised that patients required up to $15-20$ days of intensive care as the disease progressed (2). In the face of medical resource scarcities, the guideline established that everyone could not be saved from the coronavirus. And a massive death toll ensued. Yet, the challenge of taking on the coronavirus appears to be greater for the developing world. In comparison to the developed countries, resource scarcities in the developing countries are far more glaring. Due to a weaker state apparatus, the family's dependence on its providers is greater. Overall, the stakes are high. In this context of an absent social, economic and psychological safety net, this letter argues that rationing decisions should include other non-medical concerns and be made explicit in situations where all else is equal in terms of the ability to benefit from the treatment.

\section{Rationing in healthcare}

Broadly speaking, rationing in medicine refers to the denial of treatment to someone who can benefit from it (3). When the demand for healthcare exceeds its supply, rationing decisions are unavoidable. Traditionally, rationing has been implemented based on the ability to benefit from treatment. However, the present surge in demand for healthcare will mean a greater denial of treatment to potential patients. The following challenges highlight why both medical and non-medical reasons could play an important role in healthcare rationing.

\section{Existing challenges: India}

Although the Indian government has moved fast to curb its spread, there are, as on April 17,13000+ cases of the coronavirus in the country. It is also likely that community transmission of the virus already exists in certain areas. Due to India's high population density and the prevalent communitybased lifestyle, it is feared that social distancing measures are unlikely to be as effective. In the absence of large scale testing, it is possible that the true number of cases will remain unknown, and even multiply.

\section{Healthcare delivery and utilisation}

From a healthcare delivery perspective, there is a critical shortage of resources. Roughly, there is one bed for every 1000 people in the country. The highest positive estimate is that there are about 57,000 ventilators in the entire country in total (4). On top of that, social and economic challenges underlie healthcare utilisation and access. As in other developing countries, the medical system favours those who are rich and well connected. In addition, social stigma with regard to infectious diseases prevents the sick from seeking care.

\section{Consequences for the household}

Besides its health system related issues, India lacks the resources for the provision of social security mechanisms. Families excessively rely on income earners for financial support. If the sole breadwinner fails to receive treatment, the entire household could collapse.

\section{Rationing decisions}

Given these challenges, rationing decisions in the country need to be well thought out. Especially because a number of hospitalised patients are young, and even children. To those affected, immense emotional and financial losses are caused because of these decisions. Besides medical reasons, agebased and financial factors could help decide whose lives matters most in the face of these rationing decisions. This is especially important in the absence of a social, economic and 